\title{
MIDTERM CLINICAL AND ANGIOGRAPHIC RESULTS OF RADIAL ARTERY GRAFTS USED FOR MYOCARDIAL REVASCULARIZATION
}

Gianfederico Possati, MD

Mario Gaudino, MD ${ }^{\mathrm{a}}$

Francesco Alessandrini, MD

Nicola Luciani, MD

Franco Glieca, MD

Carlo Trani, $\mathrm{MD}^{\mathrm{b}}$

Carlo Cellini, $\mathrm{MD}^{\mathrm{a}}$

Carlo Canosa, $\mathrm{MD}^{\mathrm{a}}$

Germano Di Sciascio, MD
Objective: To evaluate the midterm angiographic results of the use of radial artery grafts for myocardial revascularization. Methods: The first 68 consecutive surviving patients who received a radial artery graft proximally anastomosed to the aorta at our institution were studied again at 5 years (mean $59 \pm 6.5$ months) of follow-up; 48 of these patients had previously undergone an early angiographic examination. The response of the radial artery to the endovascular infusion of serotonin was evaluated 1 and 5 years after the operation, and the midterm status of the radial artery graft was correlated with the degree of preoperative stenosis of the target vessel and with calcium-channel blocker therapy. Results: The patency and perfect patency rates of the radial artery grafts 5 years after the operation were $91.9 \%$ and $87.0 \%$, respectively. All radial artery grafts that were patent early after the operation remained patent at midterm follow-up, and early parietal irregularities in 7 patients were seen to have disappeared after 5 years. The early propensity toward graft spasm after serotonin challenge was markedly decreased at midterm follow-up. The continued use of calcium-channel antagonists after the first postoperative year did not influence the radial artery graft status, whereas the preoperative severity of the target-vessel stenosis markedly influenced the angiographic results. Conclusions: The midterm angiographic results of radial artery grafts used for myocardial revascularization are excellent. The correct surgical indication is essential. Continued therapy with calcium-channel antagonists after the first year does not influence the midterm angiographic results. (J Thorac Cardiovasc Surg 1998;116:1015-21)
A fter the first disappointing experience more than 2 decades ago, ${ }^{1}$ use of the radial artery (RA) in coronary artery bypass grafting was again proposed by Acar and colleagues in $1992 .{ }^{2}$ Since then many groups have reported encouraging short-term results with this alternative arterial conduit. ${ }^{3-7}$ To date, however, no published studies have examined the midterm angiographic fate of RA grafts used for myocardial revascularization. Our experience with the use of the RA started in

From the Departments of Cardiac Surgery a and Cardiology, Catholic University, and the Department of Cardiology, Campus Biomedico University, ${ }^{\mathrm{c}}$ Rome.

Received for publication May 20, 1998; revisions requested July 20, 1998; revisions received Aug 17, 1998; accepted for publication Sept 8, 1998.

Address for reprints: Gianfederico Possati, MD, Divisione di Cardiochirurgia, Policlinico Universitario A. Gemelli, Largo A. Gemelli 8, 00168 Rome, Italy.

Copyright (C) 1998 by Mosby, Inc.

$0022-5223 / 98 \$ 5.00+0 \quad \mathbf{1 2 / 1 / 9 4 2 8 0}$
January 1993, and the early clinical and angiographic data from the first 109 cases were published in $1996 .{ }^{8}$ We report here the 5-year clinical and angiographic results of the first 68 consecutive surviving patients in whom the RA was used as a free graft proximally anastomosed to the aorta.

\section{Patients and methods}

Patient population. From January 1993 to February 1998, 325 patients at our institution underwent myocardial revascularization with the RA as a conduit (13.4\% of the isolated coronary artery bypass procedures performed in this period). Details of the surgical technique used have already been described elsewhere. ${ }^{8}$ In this report we analyze the midterm (5-year) results of the clinical and serial angiographic studies performed on the first 68 consecutive surviving patients in whom the RA was used as a free graft proximally anastomosed to the aorta.

The main preoperative characteristics and operative data of these 68 patients are summarized in Tables I through III. Most of the patients were men, were in their sixth decade, and had 
Table I. Preoperative characteristics

\begin{tabular}{lc}
\hline Male/female ratio & $51: 17$ \\
Mean age (y) & $56.8 \pm 9.2$ \\
Risk factors & \\
Diabetes & $11(16.1 \%)$ \\
Smoking & $41(60.2 \%)$ \\
Dyslipidemia & $33(42.6 \%)$ \\
Hypertension & $29(42.6 \%)$ \\
Unstable angina & $8(11.7 \%)$ \\
Previous AMI & $44(64.7 \%)$ \\
Number of diseased vessels & $2.97 \pm 0.51$ \\
Mean ejection fraction & $0.67 \pm 0.12$ \\
\hline
\end{tabular}

$A M I$, Acute myocardial infarction.

Table II. Operative data

\begin{tabular}{lc}
\hline CPB time (min) & $63.4 \pm 16.5$ \\
Aortic crossclamp time (min) & $58.2 \pm 19.7$ \\
Number of conduits & 195 \\
Number of distal anastomoses & 224 \\
Anastomoses per patient & 3.2 \\
Number of RA anastomoses & $74^{*}$ \\
\hline
\end{tabular}

$C P B$, Cardiopulmonary bypass.

*Five sequentials.

triple-vessel coronary artery disease. The mean ejection fraction was almost normal (0.67), and only 8 patients were operated on for unstable angina.

The left internal thoracic artery (ITA) was used to revascularize the left anterior descending artery in 59 cases. The RA was mainly used on the circumflex coronary artery or on the right coronary artery. Bilateral RA harvesting was never performed. Sequential RA grafts were used in 5 patients and in 1 case the RA was divided into 2 separate grafts; the overall number of RA anastomoses performed was 74. The right ITA, the right gastroepiploic artery, and the saphenous vein were used to complete the myocardial revascularization. The mean number of anastomoses per patient was 3.2.

Long-term calcium-channel blocker therapy (diltiazem at $120 \mathrm{mg} / \mathrm{d}$ administered twice a day in the slow-release form) was prescribed at discharge from the hospital for all patients except 2 (in whom the use of this drug led to excessive systemic hypotension).

Follow-up. This study protocol was approved by the ethics committee of the Catholic University. Informed consent was obtained from all participating patients.

Patients were regularly followed up at our institution. They were required to undergo stress myocardial thallium 201 scintigraphy 6 months and 1 year after the operation and then every year thereafter. After the first year study, patients without either scintigraphic evidence of ischemia in the RA territory or angiographic demonstration of occluded RA graft ( $\mathrm{n}=$ $60)$ were randomly assigned to continue (29 patients) or suspend (31 cases) the therapy with calcium-channel blockers.

In addition, all patients were asked to undergo a continuous-wave Doppler evaluation of the forearms and an angio-
Table III. Type and distribution of distal anastomoses

\begin{tabular}{lccccr}
\hline & LITA & RITA & RGEA & $R A$ & $S V$ \\
\hline LAD & 59 & 2 & 0 & 3 & 4 \\
Diagonal & 0 & 0 & 0 & 8 & 15 \\
Intermediate branch & 3 & 0 & 0 & 5 & 9 \\
Circumflex & 0 & 0 & 0 & 38 & 11 \\
RCA & 0 & 4 & 10 & 20 & 34 \\
Total & 62 & 6 & 10 & 74 & 73 \\
\hline
\end{tabular}

LITA, Left ITA; RITA, right ITA; RGEA, right gastroepiploic artery; SV, saphenous vein; $L A D$, left anterior descending coronary artery; $R C A$, right coronary artery.

graphic study at 5 years' follow-up. Because of the observation reported by Acar and colleagues ${ }^{2}$ that RA grafts judged to be occluded at early angiography were found to be patent at a successive examination, we decided that even patients with early angiographic evidence of occluded RA grafts should undergo angiography again at midterm.

Continuous-wave Doppler evaluation of the forearm. Continuous-wave Doppler evaluation of the forearm was performed according to a previously described method. ${ }^{9}$ The peak systolic velocity (PSV), end-diastolic velocity, and resistance index of the brachial artery, ulnar artery, main artery of the thumb, and second and third common palmar digital arteries of each arm were calculated, as were those values for the RA of the side not operated on.

Angiographic study. Angiography was usually performed with $5 \mathrm{~F}$ catheters inserted through the femoral artery. A complete study of the coronary arteries and of all the implanted grafts and a left ventriculography were performed in all patients. Attention was paid to the exact correspondence of the different projections between the preoperative evaluation and all the subsequent angiographic evaluations. RA graft status at both studies was classified into 4 subgroups: (1) perfect patency, (2) patency with irregularities, (3) string sign (defined as severe and extensive narrowing of the whole body of the graft), and (4) occlusion.

In a subgroup of 19 patients the in vivo responses of the RA and left ITA grafts to the endovascular infusion of serotonin were evaluated in both early and midterm angiographic studies. For this purpose serotonin hydrochloride was selectively injected into the 2 grafts at increasing concentrations $\left(10^{-6}\right.$ and $10^{-5} \mathrm{~mol} / \mathrm{L}$ ) at a rate of $3 \mathrm{~mL} / \mathrm{min}$ for 3 minutes. At the end of the procedure, $2 \mathrm{mg}$ isosorbide dinitrate was injected into the conduits.

All measurements on angiographic images were performed with quantitative computerized angiography (Medis; Amsterdam, The Netherlands). Because this system has a lower detection limit of $0.6 \mathrm{~mm}$, structures with smaller value were considered to be $0.6 \mathrm{~mm}$ in diameter. Measurements of graft diameter were always carried out about $10 \mathrm{~mm}$ above the distal anastomosis and were carried out separately by 2 different observers blinded to treatment.

Statistical analysis. Data are expressed as mean \pm 1 standard deviation. Categoric variables were compared by the 

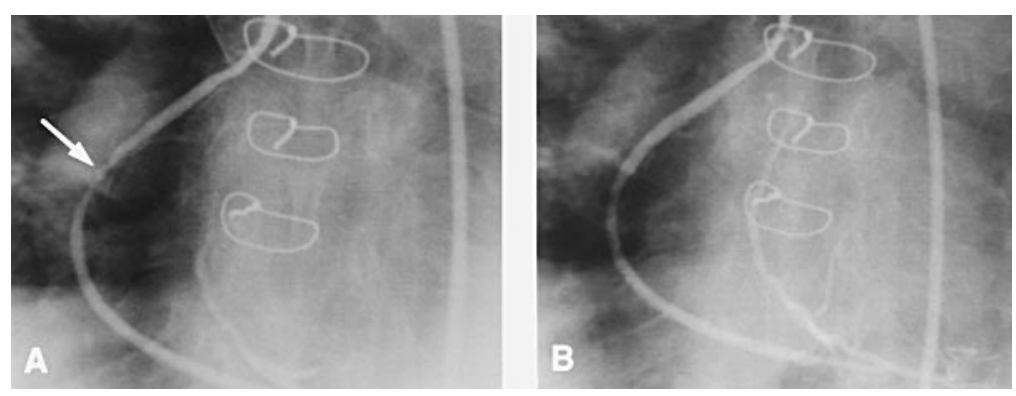

Fig 1. Successful stent angioplasty of a stenosed RA graft. A, Postoperative angiography performed 54 months after the operation demonstrated an irregular stenosis of the midtract of this RA-to-right coronary artery graft (arrow). B, This stenosis was successfully treated by means of percutaneous stent angioplasty.

Fisher exact test, whereas the Student $t$ test was used for quantitative data. RA diameter changes in response to the serotonin challenge were expressed as the percentage differences from the baseline values. RA diameters at baseline and in response to $10^{-5} \mathrm{~mol} / \mathrm{L}$ and $10^{-6} \mathrm{~mol} / \mathrm{L}$ serotonin were compared with 2-way analysis of variance for repeated measures. For $F$ values with $P<.05$, pairwise comparisons were then performed with the Newman-Keuls $t$ test for paired data. Only RA responses to the highest (vasoconstrictive) dose of serotonin were considered in this report.

\section{Results}

Clinical results. Clinical follow-up was $100 \%$ complete. Mean follow-up was $61 \pm 7.5$ months.

Two patients died of noncardiac causes (liver and colon cancer 20 and 38 months after the operation, respectively) whereas no cardiac-related deaths were reported. Among the 66 surviving patients, 60 (90.9\%) were free of angina. Five of the 6 patients in whom angina recurred underwent repeated angiography; 1 patient refused any invasive procedures. In the 5 patients who underwent further study, the causes of angina were as follows: progression of the atherosclerotic disease in ungrafted coronary vessels ( 2 cases, 23 and 31 months after the operation), stenosis of RA graft (1 case, 54 months after the operation), occlusion of ITA graft in the presence of patent RA graft ( 2 cases, 16 and 22 months after the operation).

Patients with RA stenosis and progression of the native coronary arteries successfully underwent percutaneous stent angioplasty (Fig 1), whereas the 2 patients with ITA occlusion required reoperation. All 5 patients then underwent further studies after the surgical or percutaneous procedure for the midterm follow-up.

No difference in clinical status was found between patients who continued or suspended postoperative therapy with calcium-channel blockers. Angina recurred in 3 of the 29 patients who continued therapy
Table IV. Midterm Doppler results

\begin{tabular}{|c|c|c|c|}
\hline & $\begin{array}{c}\text { Normal arm } \\
\quad(n=35)\end{array}$ & $\begin{array}{c}\text { Operated arm } \\
(n=35)\end{array}$ & $\mathrm{P}$ \\
\hline \multicolumn{4}{|c|}{ Brachial artery } \\
\hline PSV & $36.41 \pm 9.44$ & $38.63 \pm 12.58$ & NS \\
\hline EDV & $2.90 \pm 2.70$ & $2.27 \pm 2.93$ & NS \\
\hline RI & $0.92 \pm 0.08$ & $0.94 \pm 0.07$ & NS \\
\hline \multicolumn{4}{|l|}{ RA } \\
\hline PSV & $27.87 \pm 6.95$ & - & - \\
\hline EDV & $4.58 \pm 3.07$ & - & - \\
\hline RI & $0.84 \pm 0.10$ & - & - \\
\hline \multicolumn{4}{|c|}{ Ulnar artery } \\
\hline PSV & $24.00 \pm 9.89$ & $31.75 \pm 11.61$ & $<.05$ \\
\hline EDV & $4.41 \pm 3.33$ & $6.23 \pm 3.71$ & $<.05$ \\
\hline RI & $0.82 \pm 0.11$ & $0.80 \pm 0.11$ & NS \\
\hline \multicolumn{4}{|c|}{$\begin{array}{l}\text { Main artery } \\
\text { of the thumb }\end{array}$} \\
\hline PSV & $15.50 \pm 5.47$ & $12.91 \pm 4.89$ & $<.05$ \\
\hline EDV & $4.86 \pm 4.28$ & $4.00 \pm 3.39$ & NS \\
\hline RI & $0.70 \pm 0.20$ & $0.72 \pm 0.18$ & NS \\
\hline \multicolumn{4}{|c|}{$\begin{array}{l}\text { Second common } \\
\text { palmar digital artery }\end{array}$} \\
\hline PSV & $15.72 \pm 5.35$ & $15.30 \pm 6.02$ & NS \\
\hline EDV & $4.20 \pm 2.96$ & $4.61 \pm 3.30$ & NS \\
\hline RI & $0.75 \pm 0.14$ & $0.71 \pm 0.18$ & NS \\
\hline \multicolumn{4}{|c|}{$\begin{array}{l}\text { Third common } \\
\text { palmar digital artery }\end{array}$} \\
\hline PSV & $15.17 \pm 4.79$ & $13.24 \pm 3.46$ & $<.05$ \\
\hline EDV & $4.17 \pm 3.68$ & $3.04 \pm 2.80$ & NS \\
\hline RI & $0.75 \pm 0.21$ & $0.78 \pm 0.14$ & NS \\
\hline
\end{tabular}

$E D V$, End-diastolic velocity; $R I$, resistance index; $N S$, not significant.

and in 3 of the 31 patients who suspended use of the vasoactive drug. However, in 5 of these cases angina recurrence was related to failure of a non-RA graft and in only 1 case (from the continued therapy group) was angina recurrence due to RA malfunction $(P=.9)$.

Stress myocardial scintigraphy was performed in 61 cases; 5 patients without symptoms refused to undergo this investigation. Scintigraphic evidence of myocar- 
Table V. Midterm angiographic results

\begin{tabular}{|c|c|c|c|c|c|c|c|c|c|c|}
\hline & \multicolumn{2}{|c|}{ LITA $\left(n=58^{*}\right)$} & \multicolumn{2}{|c|}{ RITA $(n=4)$} & \multicolumn{2}{|c|}{$R G E A(n=10)$} & \multicolumn{2}{|c|}{$R A(n=62 \dagger)$} & \multicolumn{2}{|c|}{$S V(n=58)$} \\
\hline & No. & $\%$ & No. & $\%$ & No. & $\%$ & No. & $\%$ & No. & $\%$ \\
\hline Perfectly patent & $57^{*}$ & 98.2 & 3 & 75 & 8 & 80 & 54 & 87.0 & 40 & 68.9 \\
\hline Patent with irregularities & 0 & 0 & 0 & 0 & 0 & 0 & 1 & 1.6 & 3 & 5.1 \\
\hline String sign & 1 & 1.7 & 0 & 0 & 1 & 10 & 2 & 3.2 & 0 & 0 \\
\hline Occluded & 0 & 0 & 1 & 25 & 1 & 10 & 5 & 8.0 & 15 & 25.8 \\
\hline
\end{tabular}

LITA, left ITA; RITA, right ITA; RGEA, right gastroepiploic artery; $S V$, saphenous vein.

*Excluding the 2 patients reoperated on within 2 years after the operation because of ITA occlusion.

$\dagger$ Including the patient who underwent stent angioplasty 54 months after the operation.

Table VI. Comparison between the early and midterm angiographic studies in 48 cases

\begin{tabular}{|c|c|c|c|c|c|}
\hline \multirow[b]{2}{*}{ RA graft status } & \multicolumn{2}{|c|}{$\begin{array}{c}\text { Early } \\
\text { angiographic } \\
\text { control }\end{array}$} & \multicolumn{2}{|c|}{$\begin{array}{c}\text { Midterm } \\
\text { angiographic } \\
\text { control }\end{array}$} & \multirow[b]{2}{*}{$\mathrm{P}$} \\
\hline & No. & $\%$ & No. & $\%$ & \\
\hline Perfectly patent & 33 & 67.3 & 41 & 83.6 & .1 \\
\hline Patent with irregularities & 8 & 16.3 & 1 & 2.0 & .03 \\
\hline String sign & 2 & 4.0 & 2 & 4.0 & .6 \\
\hline Occluded & 6 & 12.2 & 5 & 10.2 & 1.0 \\
\hline
\end{tabular}

dial ischemia was detected in 16 of these 61 cases; 6 of these patients had clinical angina recurrence (as described previously), whereas 10 had asymptomatic ischemia. Silent ischemia was due to occlusion of a non-RA graft in 7 cases (5 saphenous veins, 1 right ITA, and 1 gastroepiploic artery) and to failure of RA conduit in 3 cases. In the absence of clinical ischemia, all these cases were treated medically.

With respect to the forearm status, no cases of ischemic hand complications were reported. However, 18 patients reported slight paresthesias (presumably from surgical damage to minor branches of the radial nerve) and 1 patient had tension at the elbow bend during forearm overextension (probably related to an excessive length of the skin incision). The remaining 47 patients $(71.2 \%)$ were totally free of symptoms.

Doppler results. Doppler evaluation of the forearm was performed in 35 patients at a mean interval of $57 \pm$ 8.4 months after the operation. The main Doppler results are summarized in Table IV. No important differences were reported with respect to mean PSV, enddiastolic velocity, and resistance index of the brachial artery and the second common palmar digital artery between the arm that was operated on and the contralateral arm.

The mean PSV and end-diastolic velocity of the ulnar artery were higher in the arm that was operated on (expressing the ulnar compensation for RA removal). The mean PSV of the main artery of the thumb and that of the third common palmar digital artery were lower in the arm that was operated on.

A flow gradient between the arteries of the hand of the arm that was operated on (flow higher in the medial and lower in the lateral arteries) had been seen 1 year after the operation, as has been described elsewhere. ${ }^{9}$ This gradient had disappeared at 5 years' follow-up. At that time the PSVs in the main artery of the thumb and the second and third common palmar digital arteries were almost equivalent between the 2 arms.

Angiographic results. Midterm angiographic studies were performed in 61 of the 66 cases. Four patients refused any invasive procedure ( 3 of these had no symptoms and the fourth had Canadian Cardiovascular Society class III effort angina and scintigraphic evidence of ischemia in the distribution of a saphenous vein graft). One patient was excluded because of rapidly deteriorating renal function. As in 1 patient the RA was divided in 2 separate conduits, a total of 62 RA grafts were investigated. The mean interval between operation and angiography was $59 \pm 6.5$ months.

The main angiographic results are reported in Table V. The perfect patency rate of the RA was $87.0 \%$ (54/62), compared with $68.9 \%$ for the saphenous vein and $98.2 \%$ for the left ITA ( $P=.4$ and $P=.7$, respectively). A string sign of RA grafts was reported in 2 cases.

Among the 61 cases restudied, 48 patients (49 grafts) had previously undergone early angiographic study within 1 year after the operation (mean interval $11.1 \pm$ 2.7 months). ${ }^{8}$ The comparison between the 2 angiographic studies performed in these 48 patients 1 and 5 years after the operation demonstrated that all RA grafts that were patent early after the operation remained patent at midterm follow-up (Table VI). Parietal irregularities of the proximal part of the RA graft (in close proximity to the aortic anastomosis) revealed in 7 cases by early angiography had disappeared after 5 years, and in 1 case the RA was judged 
Table VII. Comparison between the early and midterm responses to serotonin infusion

\begin{tabular}{|c|c|c|}
\hline & $R A$ & LITA \\
\hline \multicolumn{3}{|l|}{$1-y$ study } \\
\hline Baseline mean diameter (mm) & $2.11 \pm 0.10$ & $2.42 \pm 0.05$ \\
\hline $\begin{array}{l}\text { Mean diameter with serotonin } \\
(\mathrm{mm})\end{array}$ & $1.70 \pm 0.37$ & $2.41 \pm 0.17$ \\
\hline Constriction (\%) & $18.91 \pm 8.40 *$ & $0.41 \pm 0.22 \dagger$ \\
\hline \multicolumn{3}{|l|}{ 5-y study } \\
\hline Baseline mean diameter $(\mathrm{mm})$ & $2.58 \pm 0.37$ & $2.53 \pm 0.17$ \\
\hline $\begin{array}{l}\text { Mean diameter with serotonin } \\
(\mathrm{mm})\end{array}$ & $2.48 \pm 0.72$ & $2.45 \pm 0.14$ \\
\hline Constriction (\%) & $3.94 \pm 1.92 \ddagger \S$ & $3.21 \pm 0.84 \|$ \\
\hline
\end{tabular}

LITA, Left ITA.

$* P<.001$ compared with baseline and with left ITA constriction at the same time.

$\dagger P$ not significant compared with baseline.

$\ddagger P$ not significant compared with baseline and with left ITA constriction at the same time.

$\S P<.001$ compared with RA constriction at 1 year.

$\| P$ not significant compared with baseline and with left ITA constriction at 1 year.

to be occluded after 1 year but was found to be widely patent at midterm study (Figs 2 and 3). For these reasons the perfect patency rate of RA grafts increased from $67.3 \%$ to $83.6 \%$ between the first angiographic study and the second (Table VI). Moreover, the mean caliber of the RA grafts increased markedly between the 2 angiographic studies, from $2.09 \pm 0.51 \mathrm{~mm}$ at 1 year after the operation to $2.58 \pm 0.63 \mathrm{~mm}$ at 5 years' follow up $(P<.001)$.

The analysis of RA graft status at 5 years with respect to the degree of stenosis of the target vessel on preoperative angiography demonstrated that 5 of the 6 RAs used to graft target vessels with subcritical stenoses $(\leq 70 \%)$ had string sign (1 case) or occlusion (4 cases) at midterm follow-up (Fig 4). These 5 failures accounted for most of the overall cases of RA malfunction. The only case of occlusion among the patients in whom the RA was anastomosed to a vessel with stenosis greater than $70 \%$ was reported for a patient who had a severe mediastinitis early after the operation and underwent complete sternectomy and chest closure with a pectoralis major muscle flap.

The study of RA and left ITA responses to the endovascular infusion of serotonin was performed within 1 year after the operation in 19 cases. ${ }^{8}$ In 15 of these 19 cases, the same study was repeated at 5 years' follow-up. Comparison of results between the early and midterm studies showed that the vasoreactivity of RA grafts varied markedly between the first and the second angiographic investigations. In fact, early after the operation serotonin infusion led to a marked vasocon-

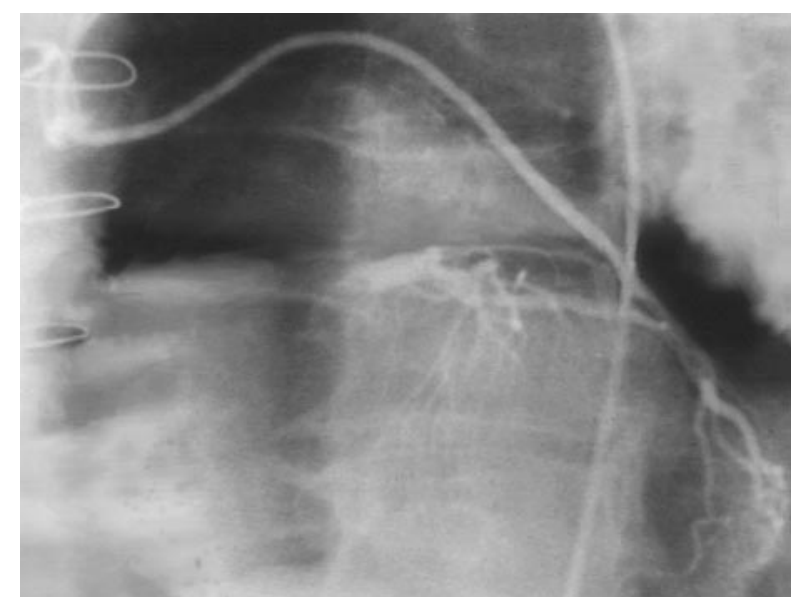

Fig 2. Patent RA graft at 5 years' follow up. It is noteworthy that control angiography performed within 1 year after the operation documented an occluded RA-to-left anterior descending coronary artery graft, whereas repeated angiography at 5 years' follow-up demonstrated a widely patent conduit.

striction of RA grafts (greater than that reported in the left ITA in the same patient), whereas after 5 years serotonin at the same doses elicited only minor RA constriction (similar to that reported in the ITA graft in the same patient; Table VII).

Finally, no difference in RA graft status could be demonstrated between patients who continued or suspended calcium-channel blocker therapy 1 year after the operation. In fact, 1 string sign was reported among the patients who suspended the calcium-channel antagonists, whereas 1 RA with string sign and 1 graft with irregularities were found in the group that continued therapy $(P=.5$ and .9 , respectively).

\section{Discussion}

Despite the good early clinical and angiographic results reported, ${ }^{2-7}$ little is known about the results of RA grafts at midterm follow-up. The effective role of this conduit in coronary surgery and its relative value with respect to other arterial grafts and to venous grafts have not yet received objective clarification. The excellent overall survival and cardiac death-free survival 5 years after the operation testify to the good cardiologic and systemic status and the relatively young age of this population consequent to our policy of using RA grafts in young patients in good condition, who provide the optimal clinical setting for the evaluation of a new arterial conduit and who are expected to receive the maximal benefit from arterial revascularization.

In our experience the overall and perfect patency rates of RA grafts at 5 years' follow-up $(91.9 \%$ and 

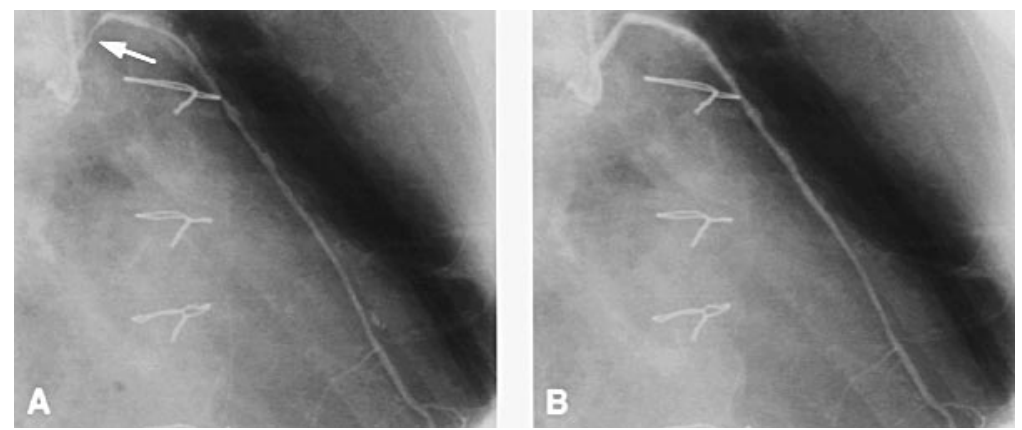

Fig 3. Resolution of RA parietal irregularities between the first and the second angiographic studies. A, One year after the operation, angiography documented evident irregularities of the proximal part of this RA graft (arrow). B, Five years after the operation, repeated angiography demonstrated the resolution of these parietal irregularities, leading to a perfectly patent graft.

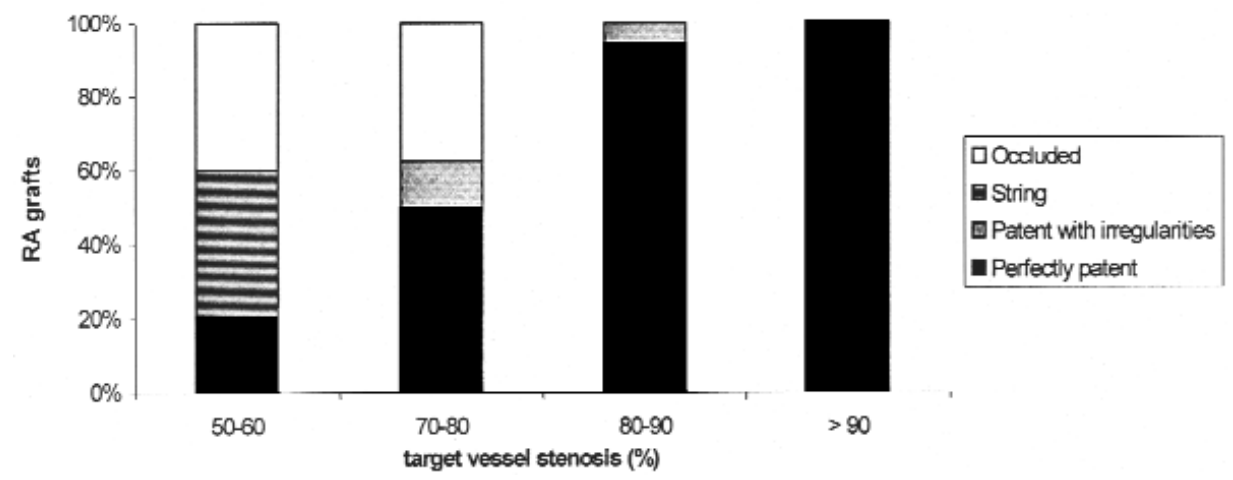

Fig 4. Status of RA grafts with respect to preoperative target-vessel stenosis.

$87.0 \%$, respectively) were slightly inferior to those achieved with the left ITA $(100 \%$ patency rate and 98.2\% perfect patency rate). However, because the left ITA was always used to graft the left anterior descending coronary artery (Table III), whereas the RA was usually anastomosed to secondary target vessels, the comparison of the angiographic results of these 2 conduits is marred by an obvious selection bias. In contrast, the saphenous vein had a target-vessel pattern more similar to that of the RA (Table III), so the comparison of the angiographic patency rates of these 2 conduits is probably more meaningful. Five years after the operation, the patency and perfect patency rates of the saphenous vein grafts were $74.1 \%$ and $68.9 \%$, respectively. These rates are consistent with those reported in most angiographic series ${ }^{10-12}$ and inferior to those achieved with the RA.

The serial angiographic study performed in the 48 patients who underwent both early and midterm repeated angiographic evaluation demonstrated that most of the parietal irregularities observed in RA grafts 1 year after the operation had disappeared at 5 years' followup, leading to an evident increase of the midterm perfect patency rate (Table VI). This observation led us to hypothesize that the abnormalities seen at early angiography were due to focal conduit spasm (rather than organic lesions), which resolved at midterm follow-up as a result of progressive loss of the RA hyperreactivity. In fact, although a high propensity toward spasm of RA grafts in the early postoperative period was demonstrated by our group in vivo ${ }^{13}$ and episodes of spasm are reported in almost all the short-term angiographic series, until now no data on the modification with time of the RA vasoreactivity have been published.

In the subgroup of patients who underwent endovascular administration of serotonin at both the early and midterm angiographic studies, we observed a marked reduction in the contractile response of RA grafts. RA grafts had become almost insensitive to serotonin by 5 years' follow-up (Table VII). Concordantly, we observed 
that both the clinical results and the midterm angiographic statuses of the RA grafts were not influenced by the use of calcium-antagonists after the first postoperative year.

In recent years several experimental and angiographic observations have underscored the importance of the site of the proximal anastomosis of the free grafts. ${ }^{4,14}$ It has been hypothesized that RA grafts proximally anastomosed to the ascending aorta are particularly vulnerable to the development of fibrous intimal hyperplasia because of the high wall stress to which they are exposed. ${ }^{4}$ In fact, intimal hyperplasia was proposed as the main cause of the high rate of RA failure in the 1970s. ${ }^{15}$

Our series shows that the angiographic results of RA grafts anastomosed to the aorta are excellent. Moreover, the evident increase with the time of RA graft diameter seems to deny the possibility of the development of a more than trivial degree of intimal hyperplasia. In addition our study testifies to the influence of the severity of target-vessel stenosis on the midterm patency of RA grafts. In fact, in our experience 4 of the 5 occlusions and 1 of the 2 string signs occurred during the first year in patients in whom the RA was used to revascularize a vessel with subcritical $(<70 \%)$ stenosis, whereas the conduits anastomosed to severely stenotic arteries had clearly superior patency and perfect patency rates (Fig 4).

It seems then likely that, in contrast to what has been reported for other conduits, ${ }^{16}$ chronic native flow competition in the early postoperative period (when the RA is highly reactive, despite therapy with calcium-channel blockers) ${ }^{13}$ can lead to RA graft malfunction and even failure (presumably from persistent graft spasm). In subsequent years the progressive loss of RA hyperreactivity can probably lead to spasm resolution and thus to disappearance of conduit irregularities and even reopening of previously closed grafts.

Finally, most patients are free of hand complications 5 years after the operation. Doppler studies of the forearm demonstrated that the removal of the RA was compensated for by an anastomotic network from the ulnar artery.

Our data show that the midterm angiographic results of RA grafts used for myocardial revascularization are excellent, superior to those achieved with the saphenous vein. A correct surgical indication (the use of this conduit to revascularize only vessels with severe stenoses) is essential. Continued therapy with calcium-channel antagonists after the first year and the performance of the proximal anastomosis to the ascending aorta do not influence the midterm angiographic status of RA grafts.

\section{REFERENCES}

1. Fisk RL, Brooks CH, Callaghan JC, Dvorkin J. Experience with the radial artery graft for coronary artery bypass. Ann Thorac Surg 1976;21:513-8.

2. Acar C, Jebara VA, Portoghese M, Beyssen B, Pagny JY, Grare P, et al. Revival of the radial artery for coronary artery bypass grafting. Ann Thorac Surg 1992;54:652-60.

3. da Costa FD, da Costa IA, Poffo R, Abuchaim D, Gaspar R, Garcia L, et al. Myocardial revascularization with the radial artery: a clinical and angiographic study. Ann Thorac Surg 1996; 62:475-80.

4. Calafiore AM, Teodori G, Di Giammarco G, D'Annunzio E, Angelini R, Vitolla G, et al. Coronary revascularization with the radial artery: new interest for an old conduit. J Card Surg 1995; 10:140-6

5. Brodman RF, Frame R, Camacho M, Hu E, Chen A, Hollinger I. Routine use of unilateral and bilateral radial arteries for coronary artery bypass graft surgery. J Am Coll Cardiol 1996;28:959-63.

6. Chen AH, Nakao T, Brodman RF, Greenberg M, Charney R, Menegus M, et al. Early postoperative angiographic assessment of radial artery grafts used for coronary artery bypass grafting. J Thorac Cardiovasc Surg 1996;111:1208-12.

7. Barner HB. Defining the role of the radial artery. Semin Thorac Cardiovasc Surg 1996;8:3-9.

8. Manasse E, Sperti G, Suma H, Canosa C, Kol A, Martinelli L, et al. Use of the radial artery for myocardial revascularization. Ann Thorac Surg 1996;62:1076-83.

9. Pola P, Serricchio M, Fiore R, Manasse E, Favuzzi A, Possati G. Safe removal of the radial artery for myocardial revascularization: a Doppler study to prevent ischemic complications to the hand. J Thorac Cardiovasc Surg 1996;112:737-44.

10. Lesperance J, Bourassa MG, Saltiel J, Campeau L, Grondin CM. Angiographic changes in aortocoronary vein grafts: lack of progression beyond the first year. Circulation 1973;48:633-43.

11. Hamby RI, Aintablian A, Handler M, Voleti C, Weisz D, Garvey JW, et al. Aortocoronary saphenous bypass grafts. Long-term patency, morphology and blood flow in patients with patent grafts early after surgery. Circulation 1979;60:901-9.

12. Campeau L, Lesperance J, Corbara F, Hermann J, Grondin C, Bourassa MG. Aortocoronary saphenous vein bypass graft changes 5 to 7 years after surgery. Circulation 1978;58:I170-5.

13. Manasse E, Sperti G, Crea F, Alessandrini F, Kol A, Canosa C, et al. Increased responsiveness to serotonin of radial artery grafts compared to internal mammary artery. In: Possati G, Suma H, Alessandrini F, editors. Proceedings of the Workshop on Arterial Conduits for Myocardial Revascularization. Perugia, Italy: Galeno Editrice; 1995. p. 57-61.

14. Massa G, Johansson S, Kimblad PO, Sjöberg T, Steen S. Might free arterial graft fail due to spasm? Ann Thorac Surg 1991; 51:94-101.

15. Curtis JJ, Stoney WS, Alford WC, Burrus GR, Thomas CS. Intimal hyperplasia: a cause of radial artery aortocoronary bypass graft failure. Ann Thorac Surg 1975;20:628-35.

16. Hashimoto H, Isshhiki T, Ikari Y, Hara K, Saeki F, Tamura T. Effects of competitive blood flow on arterial graft patency and diameter. J Thorac Cardiovasc Surg 1996;111:399-407. 